Volume 4 Nomor 1, Februari 2019, halaman 63-74

\title{
MENINGKATKAN KEMAMPUAN KOMUNIKASI MATEMATIS MAHASIWA MELALUI PEMBELAJARAN KOOPERATIF TIPE JIGSAW DALAM MATA KULIAH GEOMETRI RUANG
}

\section{IMPOVE STUDENTS' MATHEMATICAL COMMUNICATION ABILITY THROUGH JIGSAW TYPE COOPERATIVE LEARNING IN SOLID GEOMETRY COURSES}

\author{
Sumarni $^{1}$, Anggar Titis Prayitno², Mita Nurpalah ${ }^{3}$ \\ 1,2,3 Universitas Kuningan, Jln. Cut Nyak Dhien No. 36 A Kuningan Jawa Barat, \\ sumarni@uniku.ac.id, aggar.titis.prayitno@uniku.ac.id,mitanurpalah@gmail.com
}

\begin{abstract}
ABSTRAK
Tujuan dari penelitian ini adalah untuk mengkaji perbedaan rerata pencapaian dan peningkatan kemampuan komunikasi matematis mahasiswa yang memperoleh pembelajaran melalui model Jigsaw ditinjau dari kategori KAM (tinggi, sedang, rendah). Penelitian ini merupakan penelitian eksperimen, dengan desain penelitian One-Group Pretes-Posttest Design. Populasi dan sampel dalam penelitian ini adalah mahasiswa calon guru matematika di program studi pendidikan matematika Universitas Kuningan semester II tahun ajaran 2017/2018. Untuk kepentingan analisis masing-masing data penelitian dikategorikan menurut kemampuan awal matematis (KAM; tinggi, sedang, rendah). Instrumen penelitian yang digunakan adalah tes kemampuan komunikasi matematis. Analisis data menggunakan uji ANOVA satu jalur. Analisis data ditinjau berdasarkan data kategori KAM. Berdasarkan hasil analisis tersebut diperoleh kesimpulan: 1) terdapat perbedaan kemampuan komunikasi matematis mahasiswa yang memperoleh pembelajaran melalui model Jigsaw ditinjau dari kategori KAM (tinggi, sedang, rendah); 2) terdapat perbedaan peningkatan kemampuan komunikasi matematis mahasiswa yang memperoleh pembelajaran melalui model Jigsaw ditinjau dari kategori KAM (tinggi, sedang, rendah).
\end{abstract}

Kata Kunci: Kemampuan Komunikasi Matematis, Jigsaw

\begin{abstract}
The purpose of this study was to examine differences in the average achievement and improvement of mathematical communication skills of students who had learned through the Jigsaw model in terms of the KAM category (high, medium, low). This research is an experimental research, with the One-Group Pretest-Posttest Design. The population and sample in this study were prospective mathematics teacher students of mathematics education study program Universitas Kuningan in the second semester of the 2017/2018 academic year. For the sake of analysis, each research data was categorized according to the initial mathematical abilities (KAM; high, medium, low). The research instrument used was a test of mathematical communication ability. Data analysis using one-way ANOVA test. Data analysis was reviewed based on KAM category data. Based on the results of the analysis it can be concluded: 1) there are differences in mathematical communication skills of students who have learned through the Jigsaw model in terms of the KAM category (high, medium, low); 2) there are differences in the increase in mathematical communication skills of students who have learned through the Jigsaw model in terms of the KAM category (high, medium, low).
\end{abstract}

Keywords: Mathematical Communication Ability, Jigsaw 
How to Cite: Sumarni, Prayitno, A. T., \& Nurpalah, M. (2019). Meningkatkan Kemampuan Komunikasi Matematis Mahasiwa Melalui Pembelajaran Kooperatif Tipe Jigsaw dalam Mata Kuliah Geometri Ruang. Mathline: Jurnal Matematika dan Pendidikan Matematika, Vol.4, No.1, 63-74.

\section{PENDAHULUAN}

Mahasiswa program studi pendidikan matematika merupakan mahasiswa yang disiapkan untuk menjadi calon guru matematika tingkat sekolah menengah pertama (SMP) sederajat dan sekolah menengah atas (SMA) sederajat. Oleh karena itu, mahasiswa program studi pendidikan matematika dalam proses perkuliahan dibekali pengetahuan konten matematika dan pengetahuan pedagogi untuk mengajarkan matematika. Salah satu mata kuliah yang membekali pengetahuan konten matematika mahasiswa adalah Geometri Ruang.

Reys (Suherman, dkk., 2003) mengemukakan bahwa matematika merupakan suatu bahasa. Matematika sebagai suatu bahasa tentunya sangat diperlukan untuk dikomunikasikan baik secara lisan maupun tulisan sehingga informasi yang disampaikan dapat diketahui dan dipahami oleh orang lain. Oleh karena itu, mahasiswa sebagai calon guru harus memiliki kemampuan komunikasi matematis. Kemampuan komunikasi matematis penting untuk dikembangkan dalam proses pembelajaran di perkuliahan. Pentingnya kemampuan komunikasi matematis dapat dilihat dari standar kemampuan komunikasi yang ditetapkan oleh NCTM (2000), yang menetapkan bahwa standar kemampuan komunikasi matematis.

Pentingnya kemampuan komunikasi matematika juga dikemukakan Pugalee (2001) yang menyatakan bahwa dalam pembelajaran matematika, perlu dibiasakan untuk memberikan argumen untuk setiap jawabannya serta memberikan tanggapan atas jawaban yang diberikan oleh orang lain, sehingga proses pembelajarannya akan menjadi bermakna.

Berdasarkan beberapa pendapat di atas, kemampuan komunikasi matematis harus dimiliki mahasiswa untuk mengemukakan ide/gagasannya ketika berhubungan dengan orang lain atau mengungkapkan keterkaitan antarkonsep dalam matematika, keterkaitan konsep matematika dengan bidang studi lain maupun keterkaitan konsep matematik dengan kehidupan sehari-hari. Kemampuan komunikasi matematis sangat penting untuk dimiliki mahasiswa, karena dengan komunikasi matematis mahasiswa dapat mengorganisasikan kemampuan berpikir matematisnya, baik secara lisan maupun secara tulisan. 
Komunikasi dalam pembelajaran di kelas melibatkan komunikasi antara dosen dengan mahasiswa, mahasiswa dengan mahasiswa, dan antara mahasiswa dengan sumber belajar. Komunikasi merupakan kemampuan yang sangat penting dalam kegiatan pembelajaran, dan harus dikembangkan. Hal ini dikarenakan melalui komunikasi, gagasangagasan atau ide-ide menjadi objek refleksi, penghalusan, bahan diskusi dan perbaikan (NCTM, 2000). Yeager, A \& Yeager, R. (Izzati \& Suryadi, 2008) mendefinisikan komunikasi matematik sebagai kemampuan untuk mengkomunikasikan matematika baik secara lisan, visual, maupun dalam bentuk tertulis dengan menggunakan kosakata matematika yang tepat dan berbagai representasi yang sesuai, serta memperhatikan kaidahkaidah matematika. Orang tidak akan memahami konsep dan solusi suatu masalah matematika atau mungkin salah menafsirkannya jika konsep dan solusi itu tidak dikomunikasikan dengan menggunakan bahasa matematis yang tepat.

Greenes \& Schulman (Saragih, 2007) mengemukakan bahwa komunikasi matematik merupakan: (1) Kekuatan sentral bagi mahasiswa dalam merumuskan konsep dan strategi; (2) Modal keberhasilan bagi mahasiswa terhadap pendekatan dan penyelesaian dalam eksplorasi dan investigasi matematika; (3) Wadah bagi mahasiswa dalam berkomunikasi dengan temannya untuk memperoleh informasi, berbagi pikiran dan penemuan, curah pendapat, menilai dan mempertajam idea untuk meyakinkan yang lain. Berkaitan dengan peran kemampuan komunikasi, Sumarmo (2013) mengungkapkan bahwa salah satu kemampuan dasar matematika yang menjadi tujuan pembelajaran matematika adalah mengkomunikasikan gagasan dengan simbol, tabel, diagram, atau media lain untuk memperjelas keadaaan atau masalah, dalam hal ini adalah kemampuan komunikasi matematis.

Dosen mempunyai peran penting dalam merancang pembelajaran sehingga mahasiswa mempunyai kesempatan untuk berkomunikasi matematis. Agar kemampuan komunikasi matematis mahasiswa terlatih, maka mahasiswa perlu dibiasakan untuk berargumen atas setiap jawabannya dan memberikan tanggapan atas jawaban orang lain sehingga apa yang dipelajari menjadi lebih bermakna baginya (Pugalee, 2001). Selanjutnya, Brenner (1998) menemukan bahwa pembentukan kelompok-kelompok kecil memudahkan pengembangan kemampuan komunikasi matematis. Dengan adanya kelompok-kelompok kecil, maka intensitas seorang mahasiswa dalam mengemukakan pendapatnya akan semakin tinggi. Berdasarkan pendapat tersebut kemampuan komunikasi matematis dapat dikembangkan melalui pembelajaran diskusi kelompok dan presentasi 
hasil diskusi kelompok. Hal ini akan memberi peluang yang besar bagi mahasiswa untuk mengembangkan kemampuan komunikasi matematisnya.

Mahasiswa telah mempelajari materi geometri ruang dari masa sekolah, sehingga pada dasarnya mahasiswa telah memiliki pengetahuan konsep geometri ruang dalam memorinya. Oleh karena itu, proses pembelajaran diperkuliahan lebih kepada penciptaan suasana belajar yang memberikan ruang kepada mahasiswa untuk belajar secara aktif merekonstruksi pemahaman yang telah ada dalam memorinya. Selain itu, pembelajarannya yang memfasilitasi mahasiswa untuk saling berinteraksi dalam kelompok belajar untuk menuangkan pengetahuan yang ada pada memori. Sehingga, dengan belajar matematika diharapkan mahasiswa mampu meningkatkan kemampuan komunikasi matematis terkait materi geometri ruang.

Salah satu model pembelajaran yang memfasilitasi mahasiswa untuk belajar secara kelompok berdiskusi untuk menuangkan pengetahuan yang ada pada memori adalah pembelajaran kooperatif tipe jigsaw. model jigsaw adalah sebuah model belajar kooperatif yang menitik beratkan kepada kerja kelompok siswa dalam bentuk kelompok kecil, seperti yang diungkapkan Lie (2007), bahwa pembelajaran kooperatif model jigsaw ini merupakan model belajar kooperatif dengan cara belajar dalam kelompok kecil yang terdiri atas empat sampai dengan enam orang secara heterogen dan bekerja sama saling ketergantungan positif dan bertanggung jawab secara mandiri. Dalam model pembelajaran jigsaw ini mahasiswa memiliki banyak kesempatan untuk mengemukakan pendapat, dan mengolah informasi yang didapat dan dapat meningkatkan keterampilan berkomunikasi, anggota kelompok bertanggung jawab atas keberhasilan kelompoknya dan ketuntasan bagian materi yang dipelajari, dan dapat menyampaikan kepada kelompoknya (Rusman, 2008).

Dalam model pembelajaran kooperatif ini pengajar berperan sebagai fasilitator yang berfungsi sebagai jembatan penghubungan ke arah pemahaman yang lebih tinggi, dengan catatan mahasiswa sendiri. Pengajar tidak hanya memberikan penegtahuan pada siswa, tetapi harus juga membangun dalam pikirannya. Mahasiswa mempunyai kesempatan untuk mendapatkan pengetahuan langsung dalam menerapkan ide-ide meraka, ini merupakan kesempatan bagi mahasiswa untuk menemukan dan menerapkan ide-ide mereka sendiri.

Berdasarkan pemaparan di atas penulis tertarik untuk melakukan dengan judul "Meningkatkan Kemampuan Komunikasi Matematis aasiswa melalui Pembelajaran Kooperatif Tipe Jigssaw ddalam Mata Kuliah Geometri Ruang”. 


\section{METODE PENELITIAN}

Penelitian yang dilakukan merupakan penelitian eksperimen dengan One-Group Pretes-Posttest Design sebagai berikut.

$\mathrm{O}_{1}$ $\mathrm{X}$

$\mathrm{O}_{2}$

Dengan:

$\mathrm{X}=$ Pembelajaran dengan model Jigsaw

$\mathrm{O}_{1} \quad=$ Pretes

$\mathrm{O}_{2} \quad=$ Postes

Subjek dalam penelitian dilaksanakan ini adalah mahasiswa calon guru matematika di program studi pendidikan matematika Universitas Kuningan semester II tahun ajaran $2017 / 2018$.

Pengumpulan data dilakukan dengan menggunakan instrumen tes Kemampuan Matematis. Dengan indikator sebagai berikut.

(1) Menyatakan masalah dalam bentuk model matematis dari suatu permasalahan yang dinyatakan dalam bentuk gambar;

(2) Menyatakan masalah matematis kedalam bentuk model matematis berupa gambar dan grafik, menjelaskan ide, situasi dan relasi matematis.

(3) Menyatakan peristiwa sehari-hari dalam bahasa atau simbol matematis, menjelaskan ide, situasi dan relasi matematis dalam bentuk model matematika.

Untuk kepentingan analisis masing-masing data penelitian dikategorikan menurut kemampuan awal matematis (KAM; tinggi, sedang, rendah). Analisis data menggunakan uji ANOVA satu jalur. Analisis data ditinjau berdasarkan data kategori KAM.

\section{HASIL DAN PEMBAHASAN}

Data kemampuan komunikasi matematis diperoleh melalui pretes dan postes dari skor pretes dan postes selanjutnya dihitung gain ternormalisasi ( $\mathrm{N}$-gain) kemampuan komunikasi matematis mahasiswa yang pembelajarannya melalui model pembelajaran kooperatif tipe Jigsaw. Rerata N-gain yang diperoleh dari perhitungan ini merupakan gambaran peningkatan kemampuan komunikasi matematis mahasiswa yang pembelajarannya melalui model pembelajaran kooperatif tipe Jigsaw. Deskripsi rerata pretes, postes, dan N-gain kemampuan komunikasi pada kelas Jigsaw adalah sebagai berikut. 
Tabel 1. Statistik Deskriptif Kemampuan Komunikasi Matematis

\begin{tabular}{lllll}
\hline Kategori & \multirow{2}{*}{ Data Statistik } & \multicolumn{3}{c}{ Kemampuan Komunikasi } \\
KAM & & Pretes & Postes & N-gain \\
\hline \multirow{2}{*}{ Tinggi } & $\overline{\mathbf{x}}$ & 65,2 & 85,2 & 0,59 \\
& SD & 6,98 & 6,98 & 0,12 \\
\multirow{2}{*}{ Sedang } & $\overline{\mathbf{x}}$ & 44 & 64 & 0,37 \\
& SD & 0,73 & 1,08 & 0,09 \\
\multirow{2}{*}{ Rendah } & $\overline{\mathrm{x}}$ & 22,6 & 42,6 & 0,26 \\
& SD & 0,83 & 1,1 & 0,08 \\
\hline
\end{tabular}

Berdasarkan Tabel 1 di atas untuk kemampuan koneksi matematis dapat dipaparkan bahwa, rerata pretes kemampuan komunikasi matematis mahasiswa melalui pembelajaran kooperatif tipe jigsaw jika ditinjau dari mahasiswa kategori KAM, untuk katogori rendah yaitu 22,6. Sedangkan untuk kategori tinggi dan sedang, rerata pretes kemampuan komunikasi matematis mahasiswa melalui pembelajaran kooperatif tipe jigsaw masingmasing 44 dan 22,6. Rerata postes kemampuan komunikasi matematis ditinjau secara keseluruhan, rerata postes kemampuan komunikasi matematis mahasiswa melalui pembelajaran kooperatif tipe jigsaw berdasarkan KAM masing-masing yaitu 85,2, 64 dan 42,6. Ditinjau berdasarkan N-gain, terlihat bahwa rerata N-gain kemampuan komunikasi matematis kemampuan komunikasi matematis mahasiswa melalui pembelajaran kooperatif tipe jigsaw ditinjau berdasarkan kategori KAM, terlihat bahwa mahasiswa KAM tinggi, sedang dan rendah melalui pembelajaran kooperatif tipe jigsaw memperoleh rerata $\mathrm{N}$-gain masing-masing yaitu 0,59, 0,37 dan 0,26.

Hasil pengolahan uji ANOVA satu jalur dengan bantuan program SPSS 16 for windows, adalah sebagai berikut.

Tabel 2. Hasil Uji Anova Satu Jalur Kemampuan Komunikasi Matematis Berdasarkan KAM di Kelas Jigsaw

\begin{tabular}{lllll}
\hline Sumber & Df & Mean Square & $\boldsymbol{F}$ & Sig. \\
\hline Between Groups & 2 & 972,066 & 42,251 & 0,000 \\
\hline
\end{tabular}

Berdasarkan tabel 2 di atas dapat disimpulkan bahwa kategori KAM siswa memberikan pengaruh yang signifikan terhadap kemampuan komunikasi matematis siswa karena nilai Sig. lebih kecil dari $\alpha=0,05$. Berarti terdapat perbedaan rerata kemampuan komunikasi matematis secara signifikan siswa yang memperoleh pembelajaran melalui Jigsaw ditinjau dari kategori KAM (tinggi, sedang, rendah). Untuk mengetahui KAM mana yang berbeda secara signifikan dalam kemampuan komunikasi matematis dilakukan 
uji Scheffe (karena variansi kategori KAM tidak homogen). Hasil perhitungannya disajikan pada tabel berikut.

Tabel 3. Hasil Uji Scheffe Rerata Postes Kemampuan Komunikasi Matematis Berdasarkan Kategori KAM

\begin{tabular}{lllll}
\hline \multirow{2}{*}{ KAM $(\mathbf{I})$} & \multirow{2}{*}{ KAM $(\mathbf{J})$} & $\begin{array}{l}\text { Perbedaan } \\
\text { rerata }(\mathbf{I}-\mathbf{J})\end{array}$ & Sig. & Kesimpulan \\
\hline \multirow{2}{*}{ Tinggi } & Sedang & 12,518 & 0,000 & Tolak $\mathrm{H}_{0}$ \\
& Rendah & 27,800 & 0,000 & Tolak $\mathrm{H}_{0}$ \\
\multirow{2}{*}{ Sedang } & Tinggi & $-12,518$ & 0,000 & Tolak $\mathrm{H}_{0}$ \\
& Rendah & 15,282 & 0,000 & Tolak $\mathrm{H}_{0}$ \\
\multirow{2}{*}{ Rendah } & Tinggi & $-27,800$ & 0,000 & Tolak $\mathrm{H}_{0}$ \\
& Sedang & $-15,282$ & 0,000 & Tolak $\mathrm{H}_{0}$ \\
\hline
\end{tabular}

Berdasarkan Tabel 3 nilai signifikan untuk pasangan KAM 1) tinggi dan sedang, 2) tinggi dan rendah, maupun 3) sedang dan rendah adalah 0,000, ini berarti: 1) rerata skor postes kemampuan komunikasi matematis siswa yang berada pada kelompok tinggi secara signifikan lebih baik dari skor postes kemampuan komunikasi matematis kelompok sedang, 2) Untuk rerata skor postes kemampuan komunikasi matematis siswa yang berada pada kelompok tinggi secara signifikan lebih baik dari skor postes kemampuan komunikasi matematis kelompok rendah. 3) rerata skor postes kemampuan komunikasi matematis siswa yang berada pada kelompok sedang secara signifikan lebih baik dari postes kemampuan komunikasi matematis kelompok rendah.

Berdasarkan hasil analisis di atas, dapat disimpulkan bahwa perbedaan kemampuan komunikasi matematis terjadi pada siswa antara kelompok tinggi dan rendah, sedang dan rendah, tinggi dan sedang. Hasil pengolahan data N-Gain melalui uji ANOVA satu jalur dengan bantuan program SPSS 16 for windows, adalah sebagai berikut.

Tabel 4. Hasil Uji Anova Satu Jalur Kemampuan Komunikasi Matematis Berdasarkan KAM di Kelas Jigsaw.

\begin{tabular}{lllll}
\hline Sumber & $\boldsymbol{d} \boldsymbol{f}$ & Mean Square & $\boldsymbol{F}$ & Sig. \\
\hline Between Groups & 2 & 0,152 & 25.179 & 0,000 \\
\hline
\end{tabular}

Berdasarkan tabel 4 di atas dapat disimpulkan bahwa kategori KAM siswa memberikan pengaruh yang signifikan terhadap peningkatan kemampuan komunikasi matematis siswa karena nilai Sig. lebih kecil dari $\alpha=0,05$. Berarti terdapat perbedaan rerata peningkatan kemampuan komunikasi matematis secara signifikan siswa yang memperoleh pembelajaran melalui Jigsaw ditinjau dari kategori KAM (tinggi, sedang, rendah). Untuk mengetahui KAM mana yang berbeda secara signifikan dalam peningkatan 
kemampuan komunikasi matematis dilakukan uji Scheffe (karena variansi kategori KAM tidak homogen). Hasil perhitungannya disajikan pada tabel berikut.

Tabel 5. Hasil Uji Scheffe Rerata N-gain Kemampuan Komunikasi Matematis Berdasarkan Kategori KAM

\begin{tabular}{lllll}
\hline \multirow{2}{*}{ KAM $(\mathbf{I})$} & \multirow{2}{*}{ KAM $(\mathbf{J})$} & $\begin{array}{l}\text { Perbedaan } \\
\text { rerata }(\mathbf{I}-\mathbf{J})\end{array}$ & Sig. & Kesimpulan \\
\hline \multirow{2}{*}{ Tinggi } & Sedang & 0,227 & 0,000 & Tolak $\mathrm{H}_{0}$ \\
& Rendah & 0,336 & 0,000 & Tolak $\mathrm{H}_{0}$ \\
\multirow{2}{*}{ Sedang } & Tinggi & $-0,227$ & 0,000 & Tolak $\mathrm{H}_{0}$ \\
& Rendah & 0,109 & 0,036 & Tolak $\mathrm{H}_{0}$ \\
\multirow{2}{*}{ Rendah } & Tinggi & $-0,336$ & 0,000 & Tolak $\mathrm{H}_{0}$ \\
& Sedang & $-0,109$ & 0,036 & Tolak $\mathrm{H}_{0}$ \\
\hline
\end{tabular}

Berdasarkan Tabel 5 nilai signifikan untuk pasangan KAM 1) tinggi dan sedang, 2) tinggi dan rendah, maupun 3) sedang dan rendah lebih kecil dari 0,05, ini berarti: 1) rerata skor $\mathrm{N}$-gain kemampuan komunikasi matematis siswa yang berada pada kelompok tinggi secara signifikan lebih baik dari skor N-gain kemampuan komunikasi matematis kelompok sedang, 2) Untuk rerata skor N-gain kemampuan komunikasi matematis siswa yang berada pada kelompok tinggi secara signifikan lebih baik dari skor $\mathrm{N}$-gain kemampuan komunikasi matematis kelompok rendah. 3) rerata skor N-gain kemampuan komunikasi matematis siswa yang berada pada kelompok sedang secara signifikan lebih baik dari Ngain kemampuan komunikasi matematis kelompok rendah. Berdasarkan hasil analisis di atas, dapat disimpulkan bahwa perbedaan peningkatan kemampuan komunikasi matematis terjadi pada mahasiswa antara kelompok tinggi dan rendah, sedang dan rendah, tinggi dan sedang.

Berdasarkan hasil penelitian diperoleh bahwa hasil pembelajaran Jigsaw dapat meningkatkan kemampuan komunikasi matematis mahasiswa. Hal ini dibuktikan dengan rerata $\mathrm{N}$-gain kemampuan komunikasi matematis mahasiswa yang memperoleh pembelajaran dengan Jigsaw sebesar 0,52. Klasifikasi peningkatan kemampuan komunikasi matematis siswa belum mencapai klasifikasi tinggi, namun berdasarkan hasil uji statsitik diperoleh fakta bahwa pembelajaran Jigsaw dapat memberikan kontribusi terhadap pencapaian dan peningkatan kemampuan komunikasi matematis mahasiswa.

Hasil yang telah diperoleh memberikan gambaran bahwa pembelajaran Jigsaw memberikan kontribusi yang baik dalam meningkatkan kemampuan komunikasi matematis mahasiswa. Sehingga, dapat disimpulkan bahwa pembelajaran Jigsaw memiliki peran yang lebih baik dalam meningkatkan kemampuan komunikasi matematis siswa. 
Kontribusi pembelajaran Jigsaw terhadap peningkatan kemampuan komunikasi matematis, terlihat jelas pada saat pembelajaran berlangsung. Siswa terlatih kemampuan komunikasinya melalui kegiatan tanya jawab, diskusi dan persentasi. Pada tahap Diskusi Tim Ahli terjadi diskusi antar mahasiswa dalam kelompok ahli, berdiskusi mengungkapkan ide, pendapat atau gagasan dalam menyelesaikan LKS untuk menemukan suatu konsep, selain itu mahasiswa juga memberikan ilustrasi dengan menggambarkan permasalahan atau cara penyelesaian agar lebih mudah dipahami. Ilustrasi tersebut bisa dalam bentuk gambar, diagram, model matematika maupun kata-kata yang mudah dimengerti. dalam tahap Diskusi Tim Ahli dosen memfasilitasi siswa untuk mengungkapkan ide, pendapat atau gagasan mereka. Tahap pelaporan Diskusi Tim Asal siswa berdiskusi dalam kelompok asal, dalam tahap ini mahasiswa ahli mengungkapkan ide, pendapat atau gagasan dalam menyelesaikan LKS untuk menemukan suatu konsep, selain itu siswa juga memberikan ilustrasi dengan menggambarkan permasalahan atau cara penyelesaian agar lebih mudah dipahami kepada anggota kelompok asal. Ilustrasi tersebut bisa dalam bentuk gambar, diagram, model matematika maupun kata-kata yang mudah dimengerti sementara anggota kelompok mendengarkan penjelasan yang diberikan. Selain itu tahap diskusi tim ahli dan pelaporan diskusi tim asal merupakan tahap yang memfasilitasi mahasiswa untuk belajar berkomunikasi lisan.

Pembelajaran Jigsaw memfasilitasi siswa dalam kegiatan 5 Aspek komunikasi yang dikemukakan oleh Baroody (1993) yaitu representasi, mendengar, membaca, diskusi dan menulis. Sehingga pembelajaran jigsaw dapat meningkatkan kemampuan komunikasi matematis. Selain itu, dengan adanya diskusi kelompok kemampuan komunikasi siswa terus dilatih sehingga meningkatkan kemampuan komunikasi matematisnya. Hal ini sejalan dengan Brenner (1998) yang menemukan bahwa pembentukan kelompok-kelompok kecil memudahkan pengembangan kemampuan komunikasi matematis. Dengan adanya kelompok-kelompok kecil, maka intensitas seorang siswa dalam mengemukakan pendapatnya akan semakin tinggi. Hal ini memberikan peluang yang besar bagi siswa untuk mengembangkan kemampuan komunikasi matematisnya.

Selain itu penggunaan software GeoGebra dalam pembelajaran mata kuliah Geometri Ruang juga memberikan kontribusi yang baik dalam meningkatkan kemampuan komunikasi matematis mahasiswa. Melalui penggunaan GeoGebra mahasiswa dalam diskusi kelompok ahli mengkonstruksi konsep berupa definisi, rumus luas permukaan dan volume bangun ruang kubus, balok, prisma, limas, tabung, kerucut dan bola. Berikut gambaran kegiatan mahasiswa dalam penggunaan GeoGebra pada kegiatan presentasi. 

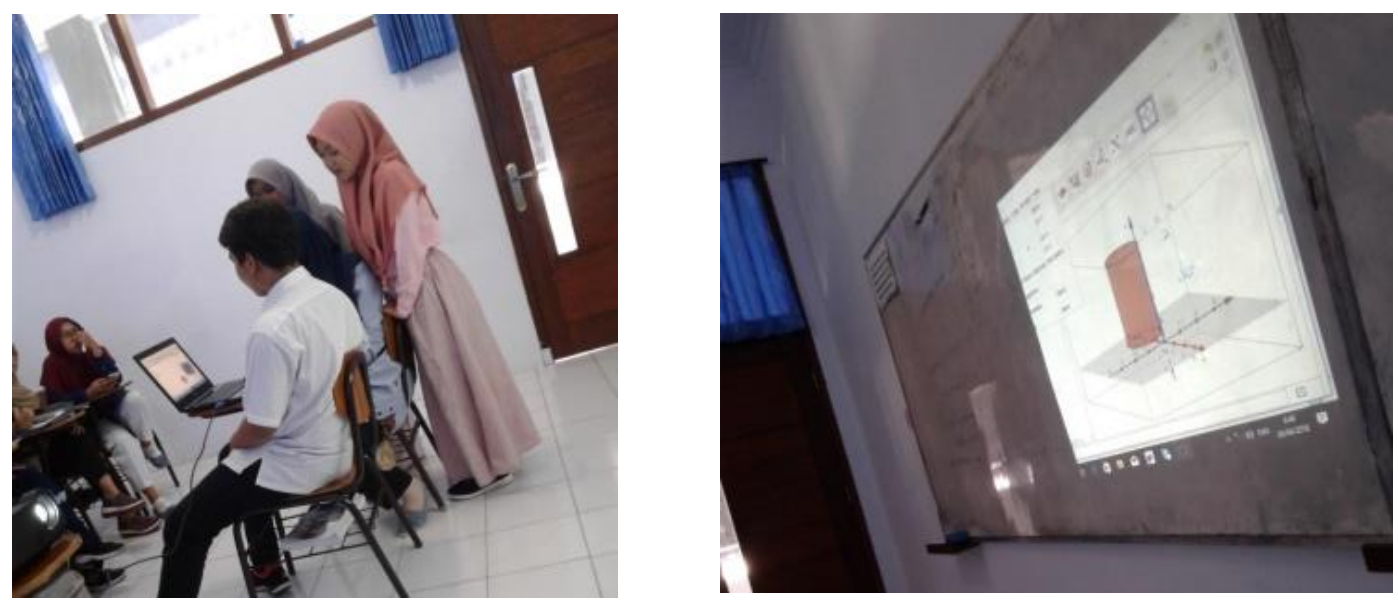

Gambar 1. Konstruksi Konsep Geometri Ruang melalui GeoGebra 5.0

\section{KESIMPULAN}

Berdasarkan analisis dan pembahasan hasil, yang telah dipaparkan pada hasil penelitian dan pembahasan, diperoleh kesimpulan sebagai berikut.

1. Terdapat perbedaan rerata kemampuan komunikasi matematis mahasiswa yang memperoleh pembelajaran melalui model Jigsaw ditinjau dari kategori KAM (tinggi, sedang, rendah).

2. Terdapat perbedaan rerata peningkatan kemampuan komunikasi matematis mahasiswa yang memperoleh pembelajaran melalui model Jigsaw ditinjau dari kategori KAM (tinggi, sedang, rendah).

Pembelajaran geometri ruang melalui Jigsaw hendaknya dijadikan sebagai salah satu alternatif pembelajaran Geometri ruang sebagai upaya untuk meningkatkan kemampuan komunikasi matematis, karena kemampuan komunikasi matematis mahasiswa masih belum maksimal, baik dalam pencapaian dan peningkatan, sehingga masih perlu untuk ditingkatkan.Selain itu, perlu dilakukan penelitian lebih lanjut mengenai penerapan Jigsaw terhadap kemampuan komunikasi matematis pada aspek/indikator yang lain, atau pengaruhnya terhadap kemampuan matematis yang lain dan kemampuan afektif yang lain.

\section{DAFTAR PUSTAKA}

Baroody, A. J. (1993). Problem Solving, Reasoning, and Communicating, K-8 Helping Children Think Mathematically. New York: Macmillan Publishing Company.

Brenner, M. E. (1998). Development of Mathematical Communication in Problem Solving Groups by Language Minority Students. Bilingual Research Journal, 22:2, 3, \& 4 Spring, Summer, \& Fall 1998, 103-128.

Izzati, N \& Suryadi, D. (2008). Komunikasi Matematik dan Pendidikan Matematika Realistik. Prosiding Seminar Nasional Matematika dan Pendidikan Matematika, Yogyakarta, UNY, 27 Nov 2010, 721-729. 
Lie, Anita. 2007. Cooperative Learning. Jakarta: Grasindo.

NCTM. (2000). Curricullum and Evaluation Standards for School Mathematics. Reston, VA: NCTM

Pugalee, D. A. (2001). Using Communication to Develop Student's Mathematical Literacy. Journal Research of Mathematics Education, 6(5), 296-299.

Rusman. (2010). Model-model Pembelajaran. Bandung: Mulia Mandiri Pers.

Saragih, S. (2007). Mengembangkan Kemampuan Berpikir Logis dan Komunikasi Matematik Siswa Sekolah Menengah Pertama Melalui Pendekatan Matematika Realistik. Disertasi. SPS UPI Bandung: tidak diterbitkan.

Suherman, E, Turmudi, Suryadi, D., Herman, T., Suhendra, Prabawanto, S., Nurjanah, \& Rohayati, A. (2003). Strategi Pembelajaran Matematika Kontemporer. Bandung: JICA.

Sumarmo, U. (2013). Kumpulan Makalah Berpikir dan Disposisi Matematik serta Pembelajarannya. Bandung: FMIPA UPI. 
74 Meningkatkan Kemampuan Komunikasi Matematis Mahasiwa Melalui Pembelajaran Kooperatif Tipe Jigsaw dalam Mata Kuliah Geometri Ruang 